\title{
Sustaining Transnational Universities as Temples of Cosmopolitan Exploration
}

\author{
Jeffrey Lehman
}

\begin{abstract}
A lesser known aspect of globalization has been the creation of a network of transnational universities. In this essay, there is an analysis for their value. Intellectual curiosity, academic freedom, and a radical openness to people who hold different worldviews-those norms are vital to humanity's efforts to meet challenges like infectious disease, climate change, and social injustice. It is vital that governments work together to recognize the benefits that follow when they refrain from trying as governments to micromanage university life. Governments are right to punish spies and thieves, people who steal military technologies, and people who hack into businesses. But they are wrong to criminalize scholars' normal contributions to, and withdrawals from, the global intellectual commons. Even more, governments must affirmatively encourage their citizens, who travel abroad as students and professors, to honor the norms of the university that is hosting them. I hope they will encourage their citizens to encounter other cultures with humility, recognizing that universal norms can express themselves in a wide variety of ways. If we are fortunate, the story of China and globalization in the year 2021 will feature the emergence of a stronger global consensus in support of the unique mission of transnational research universities.
\end{abstract}

Keywords Network of transnational universities • Intellectual curiosity •

Academic freedom $\cdot$ A radical openness to people $\cdot$ Micromanage university life $\cdot$ Criminalize scholars $\cdot$ Universal norms $\cdot$ Unique mission of transnational research universities

The University of Bologna, often described as the oldest continuously operating university, was founded in 1088. Early in its life, foreign scholars who came there to study were granted legal protections by Emperor Frederick Barbarossa. Those protections included a formal right to travel as well as immunity from responsibility for the misdeeds of their countrymen.

Across the centuries, the term "university" has been applied to many different types of institutions of higher learning, including about 25,000 today. The most

\footnotetext{
J. Lehman (凶)

New York University Shanghai, Shanghai, China

(C) The Author(s) 2021

H. Wang and A. Michie (eds.), Consensus or Conflict?, China and Globalization, https://doi.org/10.1007/978-981-16-5391-9_16
} 
widely influential, however, continue to express a certain spirit of Bologna. They welcome students from other lands to come and join with local students in a quest for insight and understanding.

The transnational quality of great universities supports both the research and the teaching dimensions of their missions. Some "indexical" academic domains (such as the humanities) concern themselves with understanding local cultures, and a diverse scholarly community helps to produce comparative insights. Other, less indexical domains (such as the natural sciences) also benefit from a more heterogeneous community, because students raised in different cultures hold different perspectives on what is salient and may even perceive the same object differently.

During the closing decades of the twentieth century and the first decade of the twenty-first, there was a broad consensus worldwide driving forward a spirit of globalization. Despite sometimes dramatic cultural, political, and economic differences among countries, each found the benefits of expanding interdependence to far outweigh the costs.

Universities embodied this spirit. Academic mobility increased at an accelerating pace, as technological progress made travel safer, swifter, and less expensive. No longer an exclusive privilege of the well-to-do, "study abroad" became normalized for a broad cross-section of students and their families around the world. According to UNESCO's Institute for Statistics, more than 30 million students pursued degrees in countries where they were not citizens in 2018. Mainland China was a key participant in this expansion of academic mobility, sending about 1 million students to study at overseas universities while hosting about 200,000 visiting students from other countries at its own universities.

Professors increased their own movement just as much as students did. Research collaborations exploded, and the norm became for scientific publications to include coauthors who had grown up in more than one country.

The accelerating academic mobility in turn helped to sustain a deepening spirit of humanism and cosmopolitanism that held up, despite trends towards increasing inequality within and among countries after 1975. Even though elites often retained strong patriotic allegiance to their nation of citizenship, they also often presented themselves as "globalists" or "internationalists," people whose loyalties transcended national borders. That phenomenon became even more visible after the end of the Cold War in 1991.

At the dawn of the twenty-first century, some universities took this transnational philosophy to new levels, establishing campus presences outside the countries of their founding. Two areas that were especially welcoming of such extensions were the Persian/Arabian Gulf and China.

In the Gulf region, one of the most ambitious early initiatives was by "Education City," established by the Qatar Foundation in Doha. Opened in 1997, the project now includes degree-granting campuses of eight universities from the United States, the United Kingdom, and France. Early in the 2000s, the United Arab Emirates recruited other American, British, and French universities to open campuses in Abu Dhabi.

Many of these campus projects created a new school devoted to only one or a small set of disciplines, such as the Weill Cornell Medical College in Qatar 
and INSEAD Abu Dhabi. A few, however, created more comprehensive research university campuses, such as NYU Abu Dhabi and Sorbonne University Abu Dhabi.

In China, an early important development was the launch of the Hopkins-Nanjing Center in 1986, a program that continues today and offers both, a two-year master's program in international studies and a one-year certificate program, in Chinese and American studies. During the 1990s and early 2000s, hundreds of new cooperative programs were set up under which foreign universities established teaching "institutes" and "programs" within traditional Chinese universities.

In 2003, China embraced an even more ambitious model, that of the SinoForeign Cooperative University ("SFCU"). Rather than being components of traditional Chinese universities, SFCU's are new legal entities, each created through a partnership between a traditional Chinese university and a non-Chinese university.

The first SFCU's were created through partnerships between Chinese universities and the University of Nottingham, Hong Kong Baptist University and the University of Liverpool. The next three involved partnerships with American Universities: NYU Shanghai, Wenzhou-Kean University and Duke Kunshan University. Since then, three more SFCU's have been established through partnerships with the Chinese University of Hong Kong, the Technion Israel Institute of Technology, and Moscow State University.

The SFCU's are, by design, experimental. Rather than being stamped from a single mold, each of the nine pursues its own vision of what a contemporary transnational university should be.

Among the nine, NYU Shanghai has received the most widespread attention within China. Since its doors opened in 2013, NYU Shanghai students have pursued undergraduate, graduate, and doctoral degrees across a wide range of disciplines in the natural sciences, social sciences, humanities, engineering, and business. From the beginning, it has been distinguished by a commitment to prepare its students to be creative cosmopolitans who can be effective participants in multicultural teams.

NYU Shanghai has pursued that commitment in several ways. As a matter of structure, half of each class of undergraduate students are Chinese; the half that come from outside China are presently drawn from more than 80 different countries. Faculty are selected through competitive global searches and hail from about 25 different countries.

First-year students must live in the residence halls, where each is assigned a roommate from another country. All classes are taught in English, but all non-Chinese students must learn Mandarin in order to graduate. Students spend their first two years on the Shanghai campus, but all are expected to spend their junior year studying in other countries.

As a matter of content, all students must complete an intellectually diverse core curriculum that immerses them in cosmopolitan philosophical values, while experiencing an active-learning pedagogy that promotes critical and creative thinking. They are, moreover, subjected to an ongoing barrage of messaging that stresses the expectation that they will function as a single, integrated student body where every student spends at least two hours every day with someone from another culture. 
From my observations, the combination of structure and content leads NYU Shanghai students to change in different ways from the changes of their counterparts at more traditional universities. When they first begin, NYU Shanghai students (whatever their nationality) are rather typical of their generation. Most have grown up in environments that nurture negative, ill-informed stereotypes about people from other countries. Moreover, in discussions about their own countries, many are quite defensive, displaying a fragile patriotism that causes them to treat others' differences in perspective and civil disagreements as micro-aggressions, causing them to miss valuable opportunities for respectful and thoughtful conversation.

After four years of intense, mandatory engagement-in the classroom and in the dorms - with classmates who come from all over the world, almost all NYU Shanghai students change dramatically. They relinquish the false stereotypes that they brought with them, and they develop a truly mature appreciation for their own countries. They no longer feel a need to see their nation as perfect and all others as defective. They understand that every country, including their own, has characteristic weaknesses and characteristic strengths. They understand that they love their own country not because it is superior but rather because it is theirs.

It is reasonable to see NYU Shanghai as an archetype of a spirit of global academic integration that was, until recently, accelerating. That spirit was sustained by three key technological and sociological features of life during that period.

The first feature was well-defined personal location. It made sense to say that, at any instant, a person was situated in a well-defined place on the planet that could be specified by longitude and latitude. Countries, in turn, were defined by mostly uncontested non-overlapping geographic boundaries. As a result, it made sense to say that a person was situated "in" only one country at a time, and the government of that country was entitled to have legal jurisdiction over them at that moment.

The second feature was well-defined military technology. Many different items in everyday use could, conceivably, be used as weapons, and many intellectual insights could, conceivably, be used both for benign purposes and also to invent more powerful weapons. Nonetheless, the nature of warfare and the pace of military technological innovation were such that it was not thought especially difficult or problematic to define "military research" clearly and narrowly.

The third feature was the non-proprietary nature of academic ideas. The insights developed at universities were global public goods. A scholar was deemed to have been productive only when their work was published-given away to the world. The human quest for understanding was understood to proceed at the level of the species, rather than at the level of the individual, the university, or the nation-state. In this regard, universities were very different from the two most important types of organization that conducted non-public research: businesses (which conducted proprietary commercial research) and armies (which conducted military research).

In those happy times, students and professors roamed the world, and the norms that governed them were clear. When in Rome, students and professors who were visiting from the University of Toronto followed Italian rules. Neither Canada's government nor the University of Toronto tried to control their behavior. Italy, for its part, did not perceive the visitors as threats. It welcomed them to participate fully in the life 
of its temples of cosmopolitanism. It fully expected that during their time as visitors they would encounter new ideas that they would bring back home and build upon in Canada.

Today, those three features no longer hold.

First, thanks to the internet, social media, and videoconference technology, people are no longer situated at discrete point-locations within the singular jurisdiction of a single country. A single classroom discussion will often include a teacher sitting in one country, talking with students who are sitting in several other countries. And even when teachers and students are physically overseas, their home governments are much less hesitant to dictate how they should behave. As a result, students frequently find themselves facing mutually inconsistent expectations - from their home government, from their fellow overseas classmates, and from the university where they are studying.

Second, the concept of "dual-use technology" has been dramatically broadened and pushed much farther upstream. As a result, a much larger percentage of the research and teaching that takes place on campus risks being perceived as "sensitive" or "secret" by cautious government officials. They, in turn, are much more likely to demand that universities prohibit non-citizens from participating in the schools' intellectual life in those domains. And they are much more likely to prohibit professors from participating in multinational research teams working in those domains.

Third, much more of the research that takes place on university campuses is being treated as proprietary. In the United States, for example, the Bayh-Dole Act of 1980 gave universities much greater responsibility and authority to commercialize inventions that were funded with government grants. Thereafter, universities rushed to set up "technology transfer offices" which, in turn, have nurtured a perception of universities as producers of commercial "intellectual property" that requires protection against unauthorized exploitation by outsiders. In an era when universities are expected to produce profitable "IP," it seems much more natural to talk about ideas being "owned" by a university, a company, and even a country.

These three shifts have coincided with the rise of nationalistic movements all around the world. Heads of state have revived modes of speech that draw strong differences between their own citizens and those from other countries. Those leaders have portrayed foreign citizens as holding different interests, often antithetical to those of domestic citizens, and insisted that foreign cultures should be viewed with suspicion. Cooperation has become tolerable only if it can be done in a manner that poses no conceivable risk to "sovereignty."

In 2020, the set of countertrends seemed to come to a head. The COVID-19 pandemic closed international borders. The language of disagreement between the governments of China and other countries-especially that of the United Statestook on a degree of overt mutual hostility that had not been seen in decades. Discussions of "decoupling" spread rapidly.

This new mindset led some government officials to insist that universities should understand themselves in national rather than transnational terms. They decried as naïve those university leaders who promote cultures of openness where scholars 
gather together to investigate topics about which they are curious and where knowledge is a public good. Instead, those officials argued that universities are national resources, with special duties to resist both corruption and exploitation at the hands of rival nations.

When NYU Shanghai was established, its American and Chinese founders believed they were early participants in an educational project that would become more and more common in the decades to come. Today, the very idea of launching a new SFCU feels somehow out of step with the nationalistic worldview that has taken hold, and it has been four years since the last SFCU was created.

My claim here is that it would be tragic for that nationalistic worldview to change the character of universities. The well-being of people and of nations calls for a thoughtful but vigorous defense of transnational universities as temples of cosmopolitan exploration.

To be sure, some of the new pressures on universities are understandable. The past few decades have intensified ideological tensions and mistrust between nations. Even more importantly, the abject failure of governments to ensure that the benefits of international cooperation are shared fairly by all their citizens has weakened the sense of common purpose. Liberalized trade in goods, services, capital, and ideas, unaccompanied by aggressive protections for those who are made worse off by such trade, has triggered exploding inequality and a dramatic diminution in quality of life for the disadvantaged.

Nevertheless, those pressures must be resisted. Undermining the identity of universities would provide no assistance whatsoever to those who were hurt by hyperglobalization. To the contrary, it would deprive humanity of resources that we very much need if we are to change course.

Universities that function as temples of cosmopolitan exploration help to sustain the flow of essential information across borders. They preserve the interaction of competing perspectives that fuels creative discovery. They maintain the personal relationships that are most effective in refuting the prejudices that inhibit human flourishing.

Such universities promote the quest for knowledge and insight in three different domains, each of which is profoundly important to the quality of human life. First, they explore the material world of natural science and technology, helping people to enjoy ever-better and ever-more-abundant food, shelter, tangible goods, physical power, and sensory delight. Second, they explore the nonmaterial world of philosophy, mathematics, history, literature, art, music, and dance, enriching "the life of the mind and spirit." Third, they explore the social world of government, economy, and interpersonal interaction, advancing the values of peace, order, and harmony.

In none of these domains, in absolutely no discipline, is it beneficial to obstruct interaction among people from different nations. Progress results from disagreement. From respectful, serious consideration of alternative ideas. From sympathetic engagement with counterargument. In order to sustain a culture of innovation, a society must find a way to ensure that its brightest minds have the habit of critical engagement with conventional wisdom. They must be able to consider how that conventional wisdom might be correct and how it might be incorrect. And they must 
have developed what the poet John Keats called "negative capability" - the capacity to hold both those considerations in mind at the same time, "without irritable reaching after fact and reason."

The historian Carl Becker memorably explained that an academic is expected to "think otherwise." That habit of mind is what allowed the world to benefit from non-Euclidean geometries, notwithstanding the genius of Euclid. It is what allowed the world to benefit from non-Newtonian physics, notwithstanding the genius of Newton. It is what allowed the world to benefit from a non-Biblical understanding of the origin of species, notwithstanding the genius of the Bible.

A temple of cosmopolitan exploration stands on the pillars of intellectual curiosity, academic freedom, and a radical openness to people who hold different worldviews. Those norms are vital to humanity's efforts to meet challenges like infectious disease, climate change and social injustice. Those same norms are equally vital to humanity's efforts to develop opportunities for all people to prosper during their lifetimes.

In this decade, I hope that governments will, together, recognize the benefits that follow when they refrain from trying to micromanage university life. Governments are right to punish spies and thieves, people who steal military technologies, and people who hack into businesses. But they are wrong to criminalize scholars' normal contributions to, and withdrawals from, the global intellectual commons.

Even more, I hope that governments will affirmatively encourage their citizens who travel abroad as students and professors to honor the norms of the university that is hosting them. I hope governments will encourage their citizens to engage respectfully with all ideas, even wrongheaded ideas. I hope they will encourage their citizens to explore critically, ideas that might be "politically incorrect," without fear of being ostracized or punished. I hope they will encourage their citizens to encounter other cultures with humility, recognizing that universal norms can express themselves in a wide variety of ways.

The story of China and globalization in the twenty-first century is not a simple story of linear progress. It is, rather, a complex story of oscillations and cycles, sometimes operating in different ways in different domains. If we are fortunate, the story of China and globalization in the year 2021 will feature the emergence of a stronger global consensus in support of the unique mission of transnational research universities.

Jeffrey Lehman is the inaugural Vice-Chancellor of NYU Shanghai and chairs the board of the American Chamber of Commerce in Shanghai. He is an internationally acclaimed leader in higher education, having served as President of Cornell University, Dean of the University of Michigan Law School, and founding Dean of the Peking University School of Transnational Law. He received MPP and JD degrees from the University of Michigan. His many honors include the NAACP Legal Defense Fund's Equal Justice Award, an honorary doctorate from Peking University, and the People's Republic of China's Friendship Award. 
Open Access This chapter is licensed under the terms of the Creative Commons AttributionNonCommercial-NoDerivatives 4.0 International License (http://creativecommons.org/licenses/bync-nd/4.0/), which permits any noncommercial use, sharing, distribution and reproduction in any medium or format, as long as you give appropriate credit to the original author(s) and the source, provide a link to the Creative Commons license and indicate if you modified the licensed material. You do not have permission under this license to share adapted material derived from this chapter or parts of it.

The images or other third party material in this chapter are included in the chapter's Creative Commons license, unless indicated otherwise in a credit line to the material. If material is not included in the chapter's Creative Commons license and your intended use is not permitted by statutory regulation or exceeds the permitted use, you will need to obtain permission directly from the copyright holder.

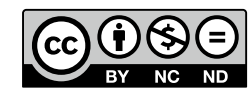

